\title{
Inteligência emocional: da revolução à controvérsia
}

Inteligência Emocional: A teoria revolucionária que redefine o que é ser inteligente, de Daniel Goleman ${ }^{1}$

Mônica F. B. Correia

Universidade Federal do Rio Grande do Norte

\begin{abstract}
7 ealizar a resenha de uma obra que se apresenta como revolucionária e extremamente controvertida não é uma tarefa - simples. Nestes termos, apresento apenas um breve resumo e pontos, baseados numa leitura crítica, a serem observados na avaliação do livro.
\end{abstract}

A obra está organizada em cinco partes: $O$ cérebro emocional, $A$ natureza da inteligência emocional, Inteligência emocional aplicada, Momentos oportunos e Alfabetização emocional. Tais partes são compostas por capítulos cujos títulos geralmente são bastante sugestivos, um verdadeiro convite para quem tem um mínimo de preocupação com a sua vida pessoal, como conhece-te a ti mesmo, escravos da paixão, a arte de viver em sociedade, casamento: inimigos intimos etc.

De forma sintética, eu diria que tais partes abordam temas relacionados à descrição do cérebro emocional e da sua evolução, o lugar e a importância das emoções e suas relações com o pensamento ou a razão (parte 1); as conseqüências destas relações, o significado e a contribuição da inteligência emocional, o controle das emoções (parte 2); as influências das heranças, experiências, sentimentos positivos e negativos, como amenizar e agir diante destas influências, os contextos 
em que a inteligência emocional poderia funcionar eficientemente (parte 3); o que é necessário aprender para formação de seres inteligentes emocionalmente, o que influi para a eficiência ou ineficiência emocional, como reverter os traumas e aprendizagens emocionais inadequadas (parte 4). E, enfim, na quinta parte, o autor procura demonstrar as conseqüências, no cotidiano e na humanidade, das deficiências emocionais, as aptidões e talentos emocionais como solução para os problemas, a importância e o como alfabetizar emocionalmente, e a instituição escolar como cenário apropriado para essa alfabetização.

Basicamente, o autor conclui sobre a necessidade, senão, impossibilidade de se viver bem, de sucesso e de eficiência nas ações e relações sem a aquisição de aptidões emocionais; fundamentando tal conclusão na evolução e funcionamento do cérebro. Essa conclusão é localizada em cada parte ou capítulo de acordo com o tema em questão. Para tanto, o autor compila investigações que têm as emoções como objeto de estudo. Refere-se a dados recentes, embora ainda inclua citações de 1899 e 1972.

A partir daqui, destacarei algumas observações referentes à linguagem utilizada pelo autor, à colocação de seus pressupostos como inovadores, à dicotomia nos seus temas centrais, à consistência dos argumentos utilizados na fundamentação e à superestimação da teoria. Anteriormente, porém, gostaria de comentar sobre a repercussão que este estudo tem alcançado, cujas dimensões são surpreendentes. A vimos citada por todos os lados, em reportagens que tentam demonstrar a sua utilização em escolas (obviamente da rede privada), depoimentos do sucesso e da importância de sua "aplicação", até a utilização em marketing de carros. Entretanto, é necessário questionar este "sucesso", pois, como o próprio autor comenta, são várias as dificuldades de implementação e manutenção da qualidade de um programa emocional, no qual exige-se capacitação de profissionais e cuidados com o mascateamento do programa pelos comerciantes da educação. Certamente tais cuidados não estão sendo considerados.

O estilo de linguagem utilizado pelo autor provavelmente favorece esta disseminação, uma vez que prioriza-se o que Goleman chama de 
linguagem emocional, cuja pretensão é atingir o coração do leitor. Este termo é constantemente referido quando fala-se da localização das emoções, mas não há esclarecimentos sobre o seu teor figurativo. Os capítulos, na grande maioria das vezes, são introduzidos com uma espécie de "historinha", e o conteúdo geralmente é extremamente didático no sentido de responder perguntas e dar conselhos ou "receitas". E, embora o público alvo e o linguajar dominante sejam o senso comum, encontramos vários termos rebuscados, o que contrasta com a freqüente utilização de expressões coloquiais como: “... mandam para o diabo que a carregue...” e “... berra até ficar rouca...”. (p. 24)

Principalmente em se considerando este público alvo, Goleman mostrou-se pouco atento para afirmações que pudessem favorecer estereótipos e/ou preconceitos “....: as meninas se tornam mais capazes que os meninos de ... fazer futricas e cometer vingancinhas dissimuladas.” ; “...; homens e mulheres têm de superar as diferenças de sexo inatas ...". Um outro exemplo refere-se à descrição de um estudo com ratos "ricos" e "pobres": "Experiências semelhantes com macacos mostram essas diferenças entre 'ricos' e 'pobres', e com certeza o mesmo efeito se dá nos seres humanos." "A diferença era tão grande que os cérebros dos ratos ricos eram mais pesados, ...". Apesar da afirmação, o autor não faz ressalvas para prevenir conclusões errôneas de déficit dos indivíduos de classes populares, embora vários estudos já tenham se ocupado em demonstrar com ênfase a falsidade de tais visões. Pode estar favorecendo ainda "rótulos" quando faz afirmações do tipo "Crianças que, na primeira e segunda séries, são agressivas e difíceis de lidar, já apresentam um protótipo de violência e criminalidade." (pp. 145, 239 e 251, respectivamente; grifo meu).

Em relação às críticas que o autor tece sobre algumas visões na Psicologia, chama atenção o caráter inovador que transparece. Porém, de maneira geral, constituem mais uma das milhares que há muito vêm-se tecendo, dirigidas a idéias atualmente abandonadas ou defendidas apenas por uma pequena minoria. Como exemplos, podemos citar a referência à explosão "inédita" de estudos científicos sobre a emoção (considerada até pelos behavioristas desde a década passada), e a repercussão de tais estudos para quem tem uma visão estreita da 
inteligência (QI). No entanto, da mesma forma, há décadas tal visão vem sendo fortemente criticada e não apenas por não levar em conta a emoção, mas muitas outras variáveis comprovadamente influenciadoras.

Ainda desta ótica, agora com relação à Educação, observou-se que, apesar de aparecer como um dos principais cenários para aplicação dos pressupostos, o autor demonstra um certo distanciamento desta área, pois cita idéias extremamente semelhantes às de estudiosos como Vygotsky e Piaget, reconhecidos atualmente como vertentes da Psicologia da Aprendizagem e do Desenvolvimento, áreas diretamente ligadas à Educação, sem, no entanto, fazer referência a eles.

Neste sentido, observamos que muitas das idéias criticadas por Goleman ou usadas para fundamentar a adequação espaço-temporal da sua obra, vêm sendo abandonadas ou não constituem mais posições majoritárias, ao contrário do que pode ser interpretado durante a leitura.

A dicotomia à qual me referi anteriormente, é sugerida quando Goleman está tratando de conceitos centrais como EMOÇ $\tilde{A O}$ e inteligência, pois hora se apresentam como constituintes, hora como funções separadas. Baseado no que o autor afirma, por vezes torna-se difícil para o leitor ver a "mente emocional" como inteligência, ou como se fossem um mesmo fenômeno: "Na verdade temos duas mentes - a que raciocina e a que sente.". Em outros momentos demonstra criticar tal separação: "Isso subverte a antiga concepção de antagonismo entre razão e sentimento ...”, então leva à dúvida sobre qual distinção pretende fazer ou criticar. (pp. 23 e 42)

Contudo, os estudos elencados nos levam a um outro nível de observação referente à metodologia ou fundamentação, ou seja, observações que refletem na consistência dos argumentos utilizados. Ao referir-se a pesquisas, por exemplo, o autor geralmente fala muito pouco sobre como elas foram realizadas ou do que podemos dizer sobre seus resultados. É possível, inclusive, encontrar descrição de resultados na qual comparam-se grupos distintos da seguinte forma: "Algumas ... Mas outros ...". Não importaria quanto de "algumas" e de "outros"? Algumas vezes, peca também por não definir termos aparentemente importantes: “... o resultado - seres humanos decentes 
- é mais crítico que nunca para o nosso futuro." Quantos significados o termo humano decente pode assumir? Desta forma, inúmeras vezes contamos apenas com informações bastante superficiais. (pp. 94 e 277)

Em outro momento, o autor refere-se ao caso de um aluno com "fantásticas aptidões intelectuais", mas que levou 10 anos para se formar, pois faltavam-lhe aptidões emocionais. Porém, aparentemente, não se levou em conta que há inúmeras outras variáveis que poderiam interferir neste fato, como nível sócio-econômico, motivação para o curso que escolhera etc., nem sempre relacionados diretamente à inteligência emocional. Sob outro ângulo, o autor também tece várias críticas aos testes psicológicos, mas se apoia em instrumentos deste tipo para argumentar em favor dos seus pressupostos, uma vez que as fantásticas aptidões intelectuais do aluno foram ditadas por um teste.

É necessário observar ainda que "os dados existentes sugerem que esse tipo de inteligência (emocional) pode ser tão ou mais valioso que o QI." Embora isso não coincida com a repercussão dos seus pressupostos, pois há dados que sugerem e há exceções, segundo o autor, que confirmam ou conduzem a determinadas hipóteses. Mas isso não autoriza uma utilização e nem tampouco uma probabilidade significativa de verdade. Nestes termos, observa-se que a dissertação é muito boa, mas por vezes leva-nos a perder de vista que ainda são conjecturas. (p. 47: grifo meu)

Outra característica observada diz respeito à grande ênfase que o autor dá ao caráter biológico, embora, à primeira vista, considere relevante a influência cultural: "Essas tendências biológicas para agir são ainda mais moldadas por nossa experiência e pela cultura". Mas, na verdade, subestima a importância da história sócio-cultural do sujeito, uma vez que geralmente ela é colocada de forma secundária e seguida de uma "tradução" biológica. Além disso, Goleman considera basicamente estudos realizados em animais ou em laboratórios, sugerindo uma certa displicência para fatores que se mostram apenas no contexto natural em que o sujeito está inserido e onde os fenômenos não podem ser observados se tratados isoladamente. Neste sentido, incorre nos mesmos erros da maioria das teorias sobre a inteligência e sua mensuração. (p. 235) 
No entanto, a "Inteligência Emocional" apresenta-se, conforme colocações do próprio Goleman, como um remédio do grande malestar instalado nas sociedades: "Acredito que o único remédio capaz de debelar esses sintomas de doença social seja uma nova forma de interagirmos no mundo - com a inteligência emocional.”; “... e ela não serve apenas como um antídoto, ....”. Do prefácio ao final do livro, o autor ocupa-se em demonstrar que está lançando o "remédio para o caos", citando as inúmeras vantagens da competência emocional. Desta maneira, coloca-o como infalível e influenciável nos mais diversos aspectos da vida humana. (p. I; grifo meu)

Em contrapartida, o autor traz vários temas em cada capítulo, especialmente na última parte, mas de forma demasiadamente sucinta. Chamam atenção observações do tipo "os leitores que não sentem atração por detalhes neurológicos talvez prefiram pular esta parte"; pois referia-se à viagem que faz pelo cérebro, na qual procura embasar os seus pressupostos, e também a mais detalhada. (p. 13)

Entretanto, a forma como escreve e o não aprofundamento (apesar de registrados aqui) não deveriam surpreender, pois o comentário na contracapa já prevenia que “... Goleman traduz as mais recentes descobertas neurológicas para o público leigo.” Ainda assim, esperavase um maior aprofundamento de como seria tal programa de competência emocional; no entanto, persistiu uma certa superficialidade. Muito embora o autor afirme que as lições emocionais e a ciência do $e u$ são os modelos que devem ser inclusos na escola num programa de educação para a competência emocional, ele não diz objetivamente que lições são essas e nem tampouco quais são os procedimentos. Desta maneira (num certo sentido) temos uma grande obra, porém ainda carente em diretrizes. (p. 286; grifo meu)

Podemos dizer que o maior mérito de Goleman foi realizar um trabalho de organização das investigações e descobertas existentes na área, o que não é uma tarefa simples, pois esta é a grande dificuldade da Psicologia: elaborar corpos de conhecimentos organizados, a respeito de determinados objetos de estudo, o que certamente levaria a contribuições mais efetivas.

Esta obra apresenta-se, então, como interessante para professores de $1^{\circ}$ e $2^{\circ}$ graus, pais e estudantes de graduação das áreas de Psicologia 
e Pedagogia - desde que não se percam de vista outros referenciais teóricos e, principalmente, uma postura constantemente crítica - uma vez que chama à atenção para a observância de comportamentos que geralmente facilitam as relações sociais e a convivência em comunidades, nas quais estamos rotineiramente inseridos.

Mônica F. B. Correia é professora do Departamento de Psicologia da Universidade Federal do Rio Grande do Norte. Mestre em Psicologia Cognitiva pela Universidade Federal de Pernambuco. Endereço para correspondência: Universidade Federal do Rio Grande do Norte, Departamento de Psicologia, Caixa Postal 1622, 59078970, Natal, RN.
${ }^{1}$ Inteligência emocional: A teoria revolucionária que redefine o que é ser inteligente, de Daniel Goleman (Rio de Janeiro: Objetiva, $1995,36^{\text {a }}$ edição, 357 páginas, R\$34,50 (Tradução do original Emotional Intelligence, Bantam Doubleday Dell Pub., 1995, por Marcos Santarrita e revisão Ana Amelia Schuquer). Daniel Goleman é norte-americano, psicólogo e doutor pela Universidade de Harvard, EUA.

Sobre o autor 